\title{
Using geospatial analysis to determine livability in Najaf city by GWR
}

\author{
Mustafa Ebraheem ${ }^{1, *}$ \\ 'Center of Urban and Regional Planning for Postgraduate, University of Baghdad, Baghdad, Iraq
}

\begin{abstract}
Iraqi cities suffer from degradation in many livable elements, sometimes related to an economic situation, social, and environmental, therefore in this research we have applied some indicators relating to livable city by using GIS technique, to determine the trend of Iraqi city in livability term. Also we are cannot depend on any foreign standards, because we did not have enough archive to our cities to explaining it is trends, so in other side the relationships between activities in the city did not have enough exploring depending on complexity model to clarify the connections among these activities and how it depends on livability of cities. We try applying GWR, on socio-economic factors, to study which effective factors on city livability. In this research we select Najaf city as a case study, for its importance as international religious tourism city, and for its stability through last decades, which has helped growth in economic activities, and made it attractive to immigrations. From discussing in literature review we determine some indicators, and finally we found the difficult point that determining Iraqi city trends in terms of livability was incomplete, because it is have a physical structure in many parts of it.
\end{abstract}

\section{Introduction}

The main problems in the Iraqi cities include decline in environmental, social, and economical circumstances, causing unlivable city, as compared to international standards. So we can make problems statements such as; (1) what are the capabilities required for a livable city experiment in Iraq, and what are obstacles around it, (2) what are the characteristics of a livable city, and (3) How we can plan for a modern city with an ability to face different problems.

Research goal knowing how far Iraqi city is from livability, also how it is near from human activates, that consternate about development elements related to man welfares life, therefore; research hypothesis are being all data for Iraqi city are nearing it to a livable city.

\section{Livable city}

The concept of the livable city is a part of a sustainable city, which constrain on many common principles, (accessibility, equality, participation, infrastructure, and others), so if we distinguish any society have participated in its governorate to take decision for building the city, we can say this is a livable city. When people have many choices of movement and are free to take trips with a variety of ways, we can say there is some indicator for livable city. However; cooperation between participating and accessibility to movement for urban economic activities, resulting in higher income, there is an increase livability level in the city [1]. In other way low rate polluted sources, attractive stability community, are more attractive for investments, visitors, and tourists, making a high level of livability in the city [2].

The livable city is a city for all ages, children have safety in playing, and elders have attractive employment opportunities.

To understand the concepts of livable city and sustainable city we can say that livability is the first stage towards sustainability. In other words, livability corresponds to the present, and sustainability to the future. Sustainability is a goal, logically to reach the goal we must have strong base in the present [3].

\subsection{Aspects of livable city}

There are many aspects, but they are different in their priority, the most important; (1) city must contain many public spaces, to be attractive and leisure, (2) priority in the centers for movement of the pedestrians, (3) having transit stations for multi purposes, and accessibility to any place, (4) diversity in housing, with reasonable costs, (5) economical competitive activities, and (6) decreasing pollution level with time.

\section{International experiences}

There are many experiences related to livability in the world, this study selects two of leader experiences in the world in terms of livable city, one of them in a wealthy country, UAE, Masdar city.

\footnotetext{
* Corresponding author: dr.mustafa.a.jalil@,iurp.uobaghdad.edu.iq
} 
The second one in a developing country with fair economic activities, Philippines

\subsection{City of Masdar}

It is one of the UAE cities; we can consider it the first city in the whole world with zero carbon and zero waste, it is the world with Solar Energy, the city build about (17) $\mathrm{Km}$ south east Abu Dhabi, near Abu Dhabi international airport, with connectivity to most other airports, and to all cities in the UAE.

Masdar city has been built based on some principles of livable city, and also sustainable city. These principles are: (1) energy management, using solar plate, descending beam, clean electricity station, (2) water management, (3) waste management and recycling, (4) recycling building martial, and (5) transportation systems, through environmental train, personal vehicle, buses and mass transit [4].

\subsection{Philippines experiences}

Philippines is one of the most crowded cities in the world, it is ranked seventh in Asia, and twelfth in the world in terms of population. The principles suitable to make Philippines a livable city are, (1) free living way to all population, (2) diversity and variety with housing, according to types and costs, to suit so everyone's need , (3) accessibility, (4) infrastructure for people with special needs, (5) job opportunities for various skill sets, (5) decreasing pollution rate, and (6) decreasing average crime rate. [5].

From these experiences, we can find out what indicators suitable to our city, and be able to manage it spatially.

\section{Geospatial analysis}

Spatial analysis now is an important tool to find out spatial indicators, so we can recognize and define areas without needing to attribute data, just depending on data related to spatial activities and their locations. The most powerful tool for that were GIS technologies, supported by remote sensing data, so by depending on basic analysis tool in GIS we can express the situation of our city through spatial indictors [6].

We must be rethinking about spatial data; we need to recognize features to find out channels among these features through a certain network. The strength of this network is related to its flow, may be passengers, goods, or any other flow that causes interaction creating interrelationship among features.

With this aim we can manipulate spatial dimensions as different shapes, by ranking the features; therefore, we can create different sizes of catchment areas. By using GIS simple analysis tool, not complicated, to represent actual situation and by explaining spatial dimensions in any location in clear language, we can ensure that GIS analysis functions are used by more people [7].

\section{Case study}

In this research (18) districts in Najaf city, have been selected as sample for finding indictors of livable city. The main reasons to select these districts were: (1) variety at district area, (2) variety of density and population, (3) variety in physical structure, (4) variety of social and economic characteristics, and (5) variety in plot shapes and area.
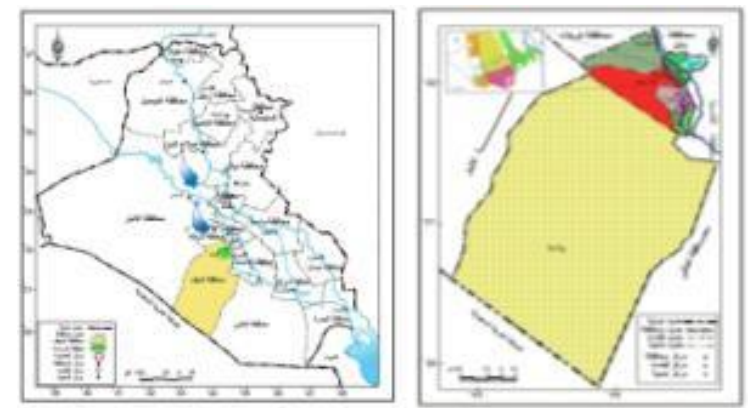

Fig. 1. City location due to Iraq and Najaf Governorate ${ }^{1}$

We can see distribution of these districts from image (2) that showing all Najaf city, and districts coding by letters, instead of names, to easy dealing with it. Note we area excluding city center from our analysis because it is represent special case due to holy shrine of Imam Ali, and the functional system is different on all other districts in the city.

\subsection{Selected indictors}

Research tries to build compromised methodology to help it getting results from real data, this compromisation depending on explanation in the previous literature review, because we cannot depending on any other city from the surrounding regions or another place in the world, because the huge different according to economic, social, and natural characteristic. Even in the same region, Iraq, because we did not have similar study or specialized center to depending it is criteria or scale.

Research depend on indicators can be measured, also measuring it in the same unit, to prevent any cumulative or bias errors in the model interpretation later. All seven indicators represent the important indicators in the city, but we must sure there are other unknown indicators effects on the livability of any city; we can see indicators as follow:
${ }^{1}$ All maps produced based on GIS system build from researchers with of physical planning. 


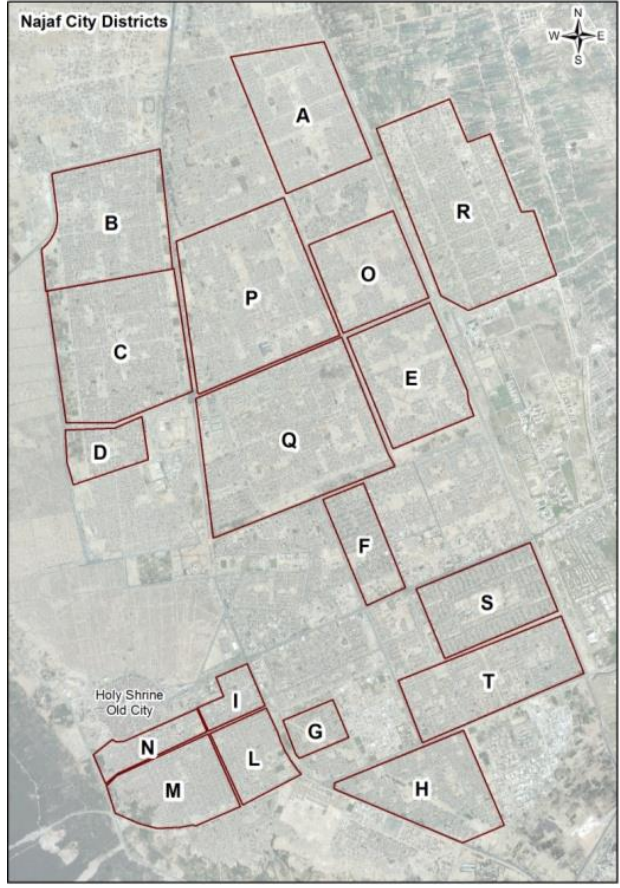

Fig. 2. Slected district to field study

Source: researcher depending on image and felid investigations.

\subsection{Commercial indicators}

The commercial land use reflect the economic situations of any district, so it is make this district desire for living, because more commercial land use meaning more chances of work and getting high income. The commercial land use must be attractive indicators to the district, but when the reaching to the critical point, we occurring theme negative indictors because the side effects be decay all districts services.

Fig. (3), showing distribution of commercial land use on districts, we can notice from all five category of distributing commercial land use the districts (Q and E) have the maximum share of this land use, and in the other side the districts (A, D, G, H, S, T, ) have the minimum share of this land use.

\subsection{Green Area indicators}

This indicator have positive relationship with livable city, increasing this indicator effecting on all activities in the city, research indicate all active green area in the city districts, we can also depending this indicators as attractive elements to resident in the district. From the Fig. (4), we can recognizing the maximum green area land use in $(\mathrm{C})$ districts, and minimum land use in (A, E, F, G, H, I, L, M, N, O, R, S, and T) districts.

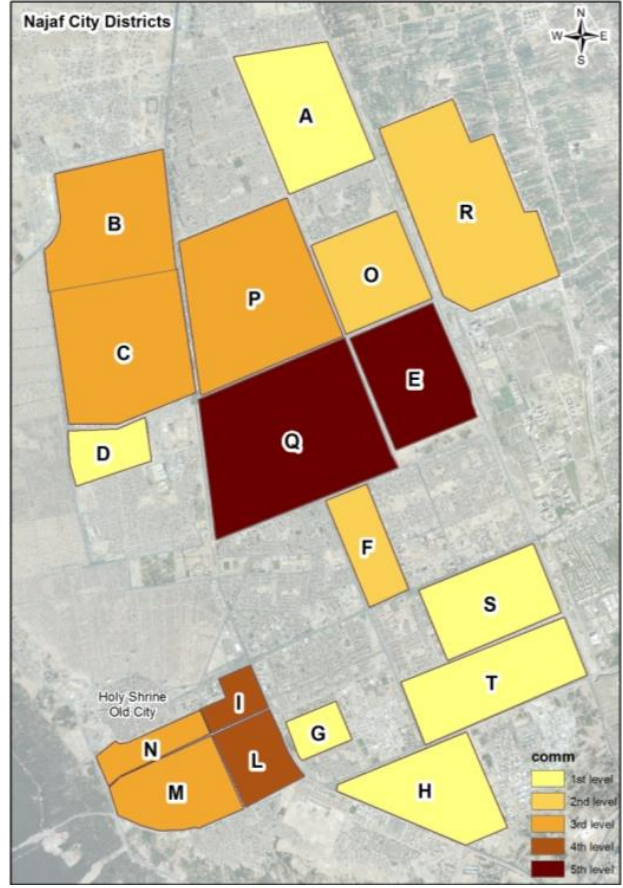

Fig. 3. Spatial indicatores trend of Commercial Landuse

Source: researcher depending on image and felid investigations.

\subsection{Mass transit indicators}

These indicators express on accessibility level to the city through time, also it is positive relationship with livable city, we calculating this indicator by representing all mass transit paths in the city, the mass transit related to paths of public vehicles in the districts, means the long of the paths represent quality of mass transit, usually when mass transit related to private sector only, we'll find it have relation with distracts attractive to resident. We can notice from Fig. (5) that district (C) have maximum value from the five category of mass transport, when in the other side, distracts $(B, F, G, M$, $\mathrm{O}$, and $\mathrm{R}$ ) recording minimum value of mass transport.

\subsection{Population Density indicators}

The population density showing to us the reality of district attractive and population willing to get residents, therefore; naturally the districts with high density means there are many good conditions in this district, so be attractive for people, but low density surly that means the district unattractive. Fig. (6), showing us that districts $(\mathrm{C}$, and $\mathrm{O}$ ) have high proportion of population density, where the districts (A, D, E, F, G, P, Q, R, S, and T) have very low density. 


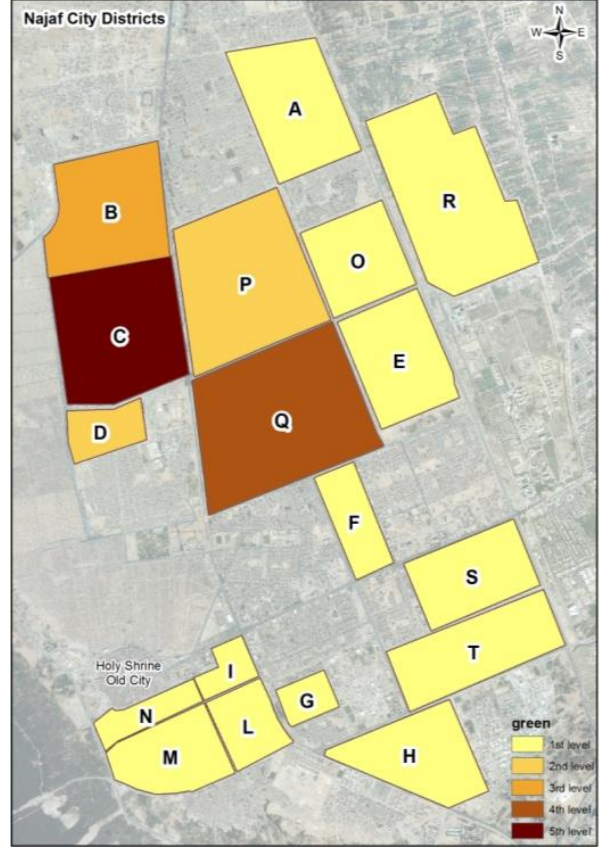

Fig. 4. Spatial indicatores trend of Green Area

Source: researcher depending on image and felid investigations.

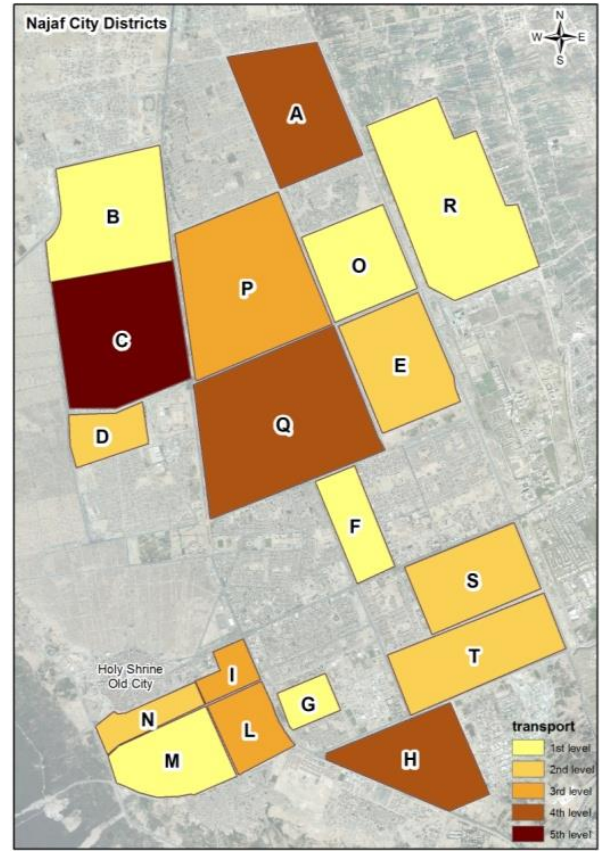

Fig. 5. Spatial indicatores trend of Public Transportation

Source: researcher depending on image and felid investigations.

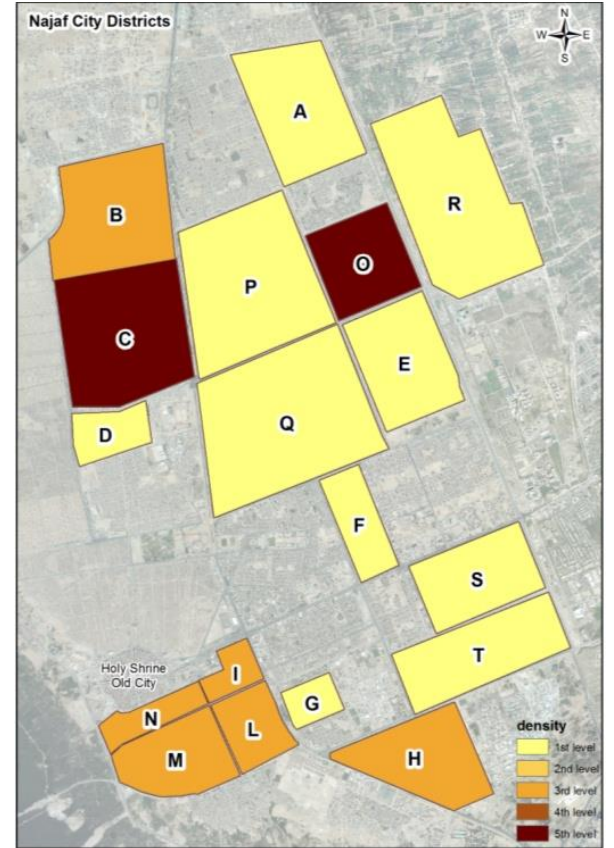

Fig. 6. Spatial indicatores trend of Population Density

Source: researcher depending on image and felid investigations.

\subsection{Road Network indicators}

This indicator refer to accessibility in the districts, so the distance of all major roads may showing us how district have accesses, intersections, and links, to be easy the movement among district parts. Fig. (7) clarifies that district ( $\mathrm{M}$ and $\mathrm{R}$ ) have maximum value of roads network, and districts (D, F, G, I, and N) have minimum value of it.

\subsection{Services indicators}

This indicator consist of all services provides in district, education, health, cultural, and recreation, mainly if these services are good and available the district will attractive to populations, Fig. (8), showing that high value of availability services in the districts $(\mathrm{P}$ and $\mathrm{Q})$, and districts $(\mathrm{C}, \mathrm{D}, \mathrm{G}, \mathrm{I}, \mathrm{L}, \mathrm{M}$, and $\mathrm{N})$ recorded minimum value of service availability.

\subsection{District area indicators}

We are using this indicator as representative of difficulty in the providing any service, so the area of district almost it causing reversely in attractive population, because when area is high needing more efforts to be suitable to livability, but if be small the services in it, was controlled easier, Fig. (9), showing high districts area in $(\mathrm{P}, \mathrm{Q}$, and $\mathrm{R})$, and small area with districts $(\mathrm{D}, \mathrm{F}$, I, L, G, and N). 


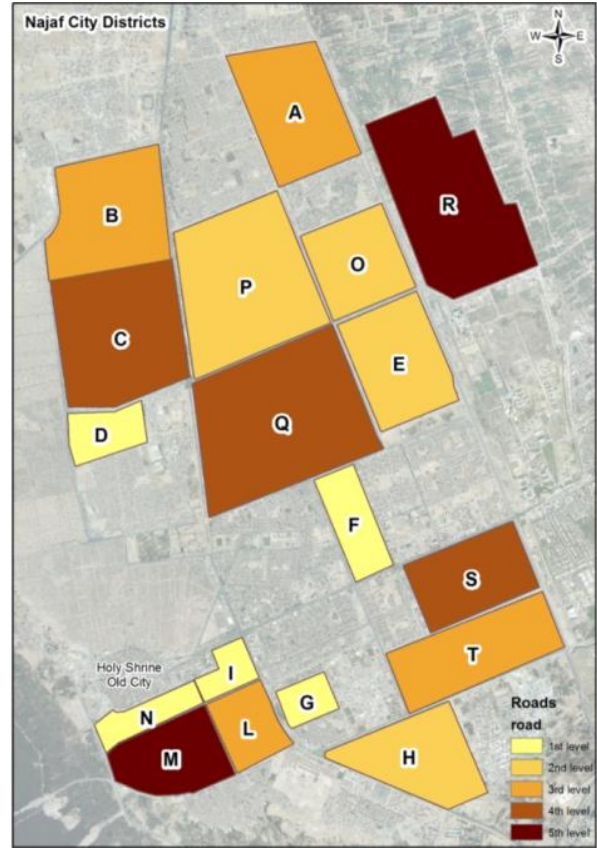

Fig. 7. Spatial indicatores trend of Roads Network

Source: researcher depending on image and felid investigations.

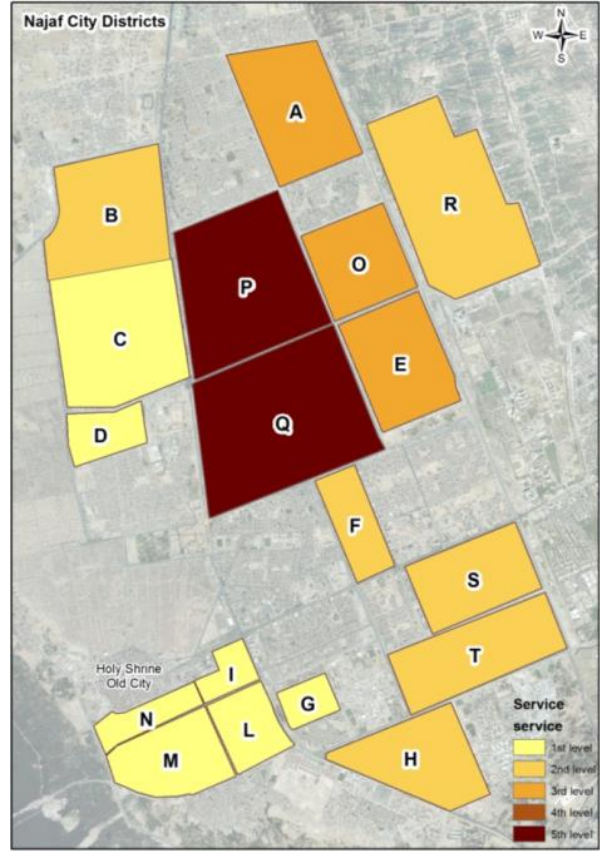

Fig. 8. Spatial indicatores trend of Service

Source: researcher depending on image and felid investigations.

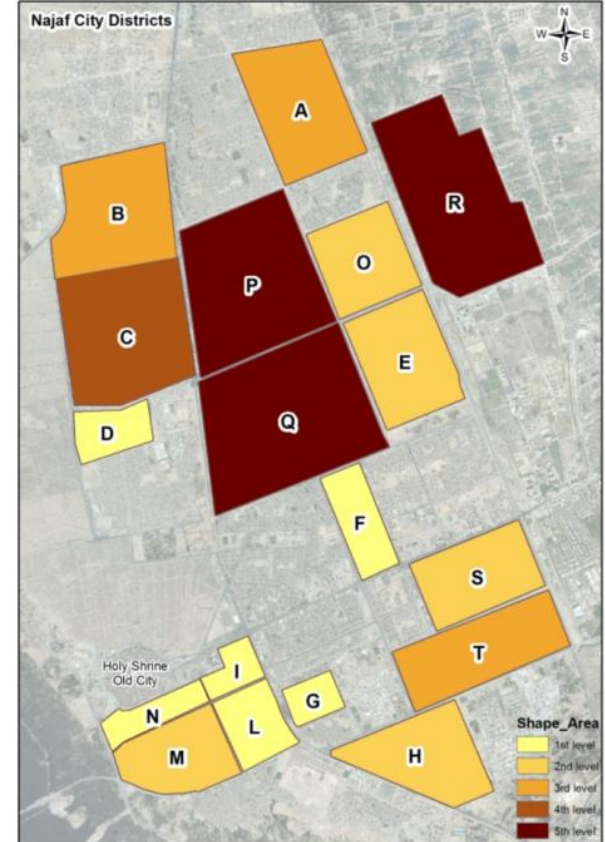

Fig. 9. Spatial indicatores trend of Districts Area

Source: researcher depending on image and felid investigations.

\subsection{Review indicators}

From all perviuose review to all indictors, we can shwo in Fig. (10), behaviore of indicitors with districts. We found that district $(\mathrm{C}$ and $\mathrm{Q})$ have three maximum value, when districts ( $\mathrm{P}$ and $\mathrm{R}$ ) have just two maximum value, and the recent district have one or no maximum value, so logically we found the best districts for livabilty are (C and Q), also table refering to no relation among population density and other indicatores, for that, distric $(\mathrm{C}$ and $\mathrm{O}$ ) have maximum value of population density, but at the same time all other indicatores were in minimum value, espically to $(\mathrm{O})$ district.

\section{Applying GWR Model}

We are must define parameters of GWR model, by determine dependent variable, in our case, we are selecting (Population Density) as occurring it dependent variables. This variable referring to population willing to live in the certain district than other, so the condition system related to live daily circulation in this district, who it is density, is high, sure must be better than other districts, so, the livability of this district is more than others.

For previous discussion we selecting GWR, because it is capable to explain the effect of any variable on livability level separately with remaining in mind these spreading do not mean works alone without interrelationships affecting on and among Model variables.

The independent viarables can may see it in table (1). 


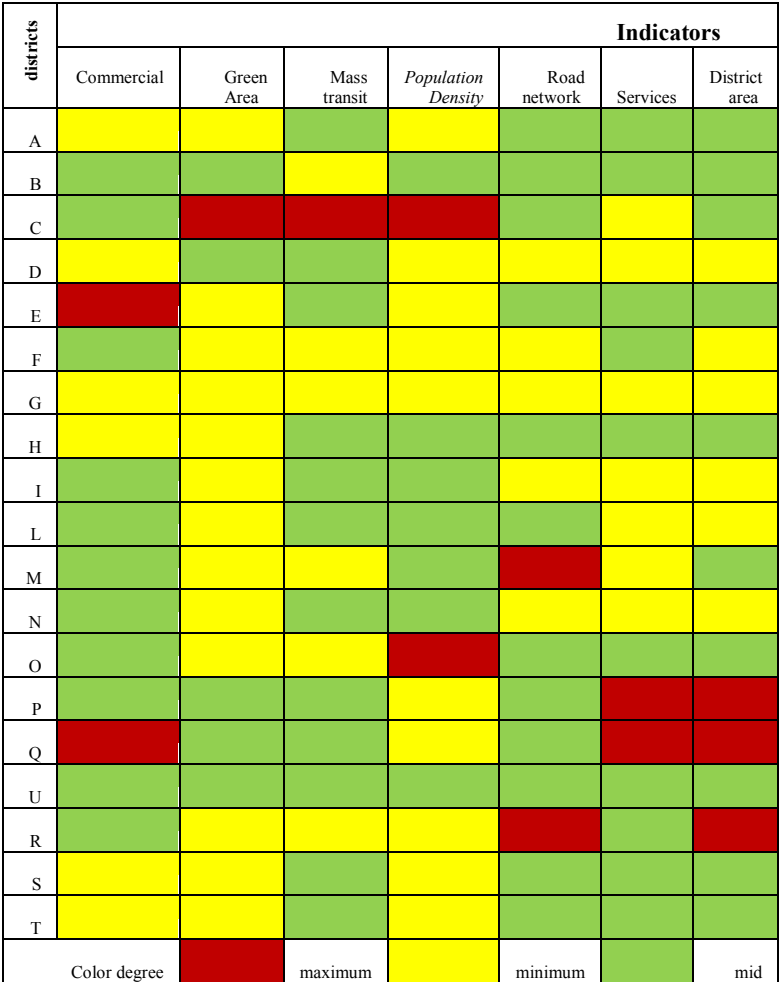

Fig. 10. Indicators relationships with districts

Source: researcher.

Tab 1. GWR model varibles

\begin{tabular}{|c|c|c|}
\hline Variables & Type & Explain \\
\hline $\begin{array}{c}\text { Population } \\
\text { density }\end{array}$ & Dependent & $\begin{array}{c}\text { The willing to live in } \\
\text { the district }\end{array}$ \\
\hline Commercial & Independent & $\begin{array}{c}\text { Describing availability } \\
\text { of works, and income } \\
\text { level }\end{array}$ \\
\hline $\begin{array}{c}\text { Green } \\
\text { Area }\end{array}$ & Independent & $\begin{array}{c}\text { Referring to good } \\
\text { quality of live without } \\
\text { pollution and have may } \\
\text { chance for recreation }\end{array}$ \\
\hline $\begin{array}{c}\text { Mass } \\
\text { transit }\end{array}$ & Independent & $\begin{array}{c}\text { Meaning accessibility } \\
\text { in movements }\end{array}$ \\
\hline $\begin{array}{c}\text { Road } \\
\text { network }\end{array}$ & Independent & $\begin{array}{c}\text { Infrastructure for } \\
\text { movement }\end{array}$ \\
\hline $\begin{array}{c}\text { Services } \\
\text { Independent }\end{array}$ & $\begin{array}{c}\text { The import conditions } \\
\text { to stability }\end{array}$ \\
\hline $\begin{array}{c}\text { District } \\
\text { area }\end{array}$ & Independent & $\begin{array}{c}\text { The cost of } \\
\text { rehabilitations }\end{array}$ \\
\hline
\end{tabular}

Source: researcher.

Firstly, the most important thing after running variables in the model was checking Spatial Validity of model; this will be through applying (Moran I) on the residuals of GWR model.

The (Moran I) will discovering the Spatial Autocorrelation among variables through spatial distribution of them, if apparent ant concentration, meaning the model was no have confidently, which means, there are other variable effective in essential way on model behavior. Fig. (11) Showing the result of (Moran I) to our model, and it is describe behavior of our variables are Spatial Randomly Distributed, meaning our model have true variables and related to logic of our study problem.

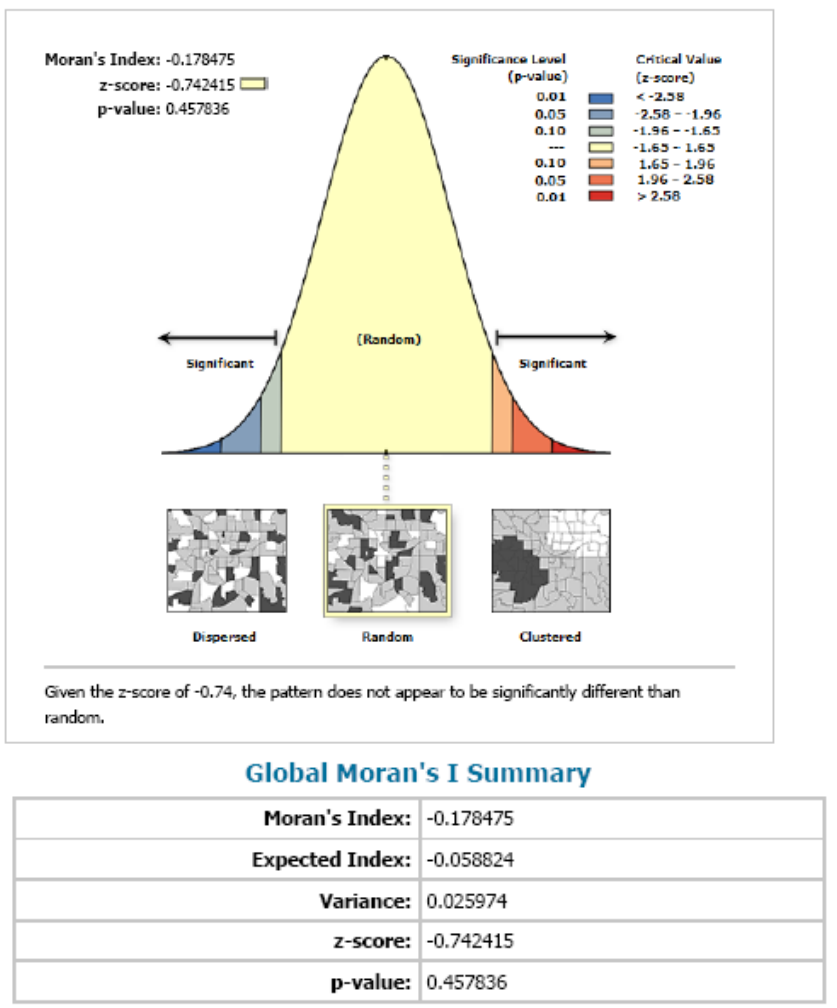

Fig. 11. results of applying Moran I on residuals of GWR Model

Source: researcher depending on running Moran I.

Secondly, discussing results of GWR, table (2), are showing the main results of model. The important one, the value of $R^{2}$, this value define to strength of explaining relationship through model, in our case it was $23 \%$, this value is accepted, when occurring we dealing with man behavior, and surly there are many many systems effecting on the urban life. The result of Sigma is good, and may be bettering it, when it is value minimizes, by taking more variables.

Thirdly, we can from table (3) clarify the behavior of independent variables, when it working together as system to effect on the independent variable, the Population Density.

We distinguish that two variables reversely effective on the dependent variables, District Area and Services, and the other four variables have direct effecting on increasing population density, in the first level we found road network was more effecting than other, then the commercial land use, with mass transit, and lastly the Green Area. 
Tab 2. results of GWR model.

\begin{tabular}{|c|c|}
\hline subject & value \\
\hline Bandwidth & 90277.505 \\
\hline ResidualSquares & 926758.491 \\
\hline EffectiveNumber & 7.0213 \\
\hline Sigma & 290.542 \\
\hline AICc & 278.446 \\
\hline R2 & 0.23238 \\
\hline R2Adjusted & -0.18862 \\
\hline
\end{tabular}

Source: researcher depending on running GWR model

Tab 3. Resultes of GWR model equation parameters

\begin{tabular}{|c|c|}
\hline variables & values \\
\hline Intercept & 353.64062481539 \\
\hline Commercial & 0.00118731451 \\
\hline Services & -0.00029769160 \\
\hline Road Network & 0.01217881478 \\
\hline Mass transit & 0.00236091701 \\
\hline Green Area & 0.00084879463 \\
\hline District area & -0.00008052649 \\
\hline
\end{tabular}

Source: researcher depending on running GWR model

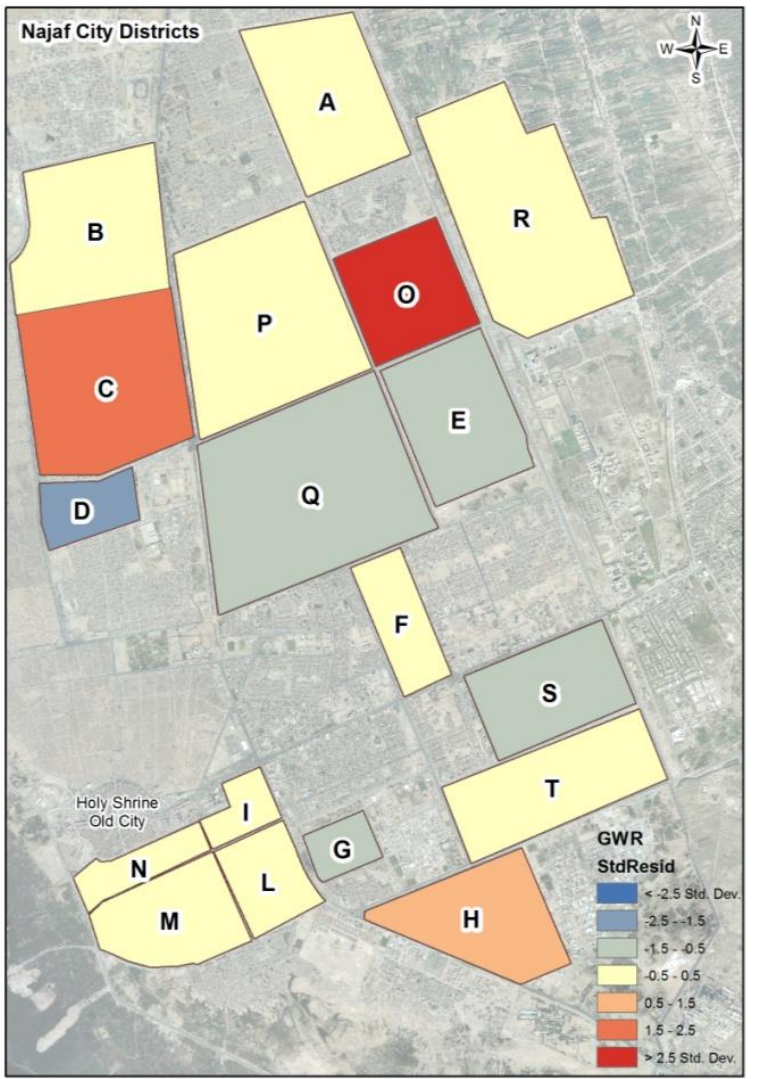

Fig. 12. Spatial indicatores of GWR Analysis Results

Source: researcher depending on image and felid investigations.

\section{Conclusions}

1- We can express on livability by some electing indicators, conditioning these indicators suitable with city situation.

2- The difficulties through measuring liaveablity were not collecting data, but comparing the results with base line.

3- Best way to monitor trend of any city livability through comparing it is situation with time.

4- We cannot found main measured variable can express on city livability directly.

5- Measuring levels of livability are clarifying city systems trend work during the time.

6- Livable city characteristics are safety and free with variety choices.

7- Major consideration of the livability related to movement system, with all kinds and types.

\section{$8 \quad$ Recommendations}

1- We can compromise among group of variables to define indicator can expressing clearly about city livability.

2- Must are represent cities livability yearly by charts and monitoring it.

3- We can maximize confidence by increasing cases and independent variables

4- The logic of building model are most important than measuring variables.

\section{References}

1. E. Momtaz, in ITAME Conf. Proc., (UAE 2015).

2. L. Sabra, Downtown living for families, The Vancouver, BC Urban Liveability Experience and Lessons for Other Cities, M.Sc., (UoW2008).

3. Lowe \& others, Place, HLRP,1, (2013)

4. A. Yones, $E A J$, Measuring and analysis welfare in Karkok city and related to distributing income for 2009 , no 83, (2010).

5. https://dmciphilippines.wordpress.com.

6. K. Kemp, Encyclopaedia GIS, (Sage Publications 2008).

7. B. Burian, Advances in spatial planning, InTech, 9, 51000, (Croatia 2012). 